\title{
Quality of life information and trust in physicians among families of children with life-limiting conditions
}

This article was published in the following Dove Press journal:

Patient Related Outcome Measures

30 September 2010

Number of times this article has been viewed

\author{
I-Chan Huang ${ }^{1,2}$ \\ Kelly M Kenzik' \\ Tuli Y Sanjeev ${ }^{3}$ \\ Patricia D Shearer ${ }^{3}$ \\ Dennis A Revicki ${ }^{4}$ \\ John A Nackashi ${ }^{3}$ \\ Elizabeth A Shenkman ${ }^{1,2}$ \\ 'Department of Health Outcomes \\ and Policy, ${ }^{2}$ Institute for Child Health \\ Policy, ${ }^{3}$ Department of Pediatrics, \\ College of Medicine, University of \\ Florida, Gainesville, Florida; ${ }^{4}$ United \\ BioSource Corporation, Maryland, \\ USA
}

Purpose: To examine information that parents of children with life-limiting conditions want to discuss with children's physicians to assist decision-making, and whether the desire for this information is associated with parents' trust in physicians.

Study design: A cross-sectional study using a telephone survey.

Patients and methods: Subjects comprised a random sample of 266 parents whose children were enrolled in Florida's Medicaid Program. Parents were asked if they wanted to discuss information related to their children's treatment, including quality of life (QOL), pain relief, spiritual beliefs, clinical diagnosis/laboratory data, changes in the child's behavior due to treatment, changes in the child's appearance due to treatment, chances of recovery, and advice from the physician and family/friends. The Wake Forest Physician Trust Scale was used to measure parents' trust in physicians. We tested the relationships between parents' age, race/ethnicity, education, parent-reported children's health status, and the desired information. We also tested whether the desire for information was associated with greater trust in physicians.

Results: Most parents wanted information on their children's QOL (95\%), followed by chance of recovery (88\%), and pain relief (84\%). Compared with nonHispanic whites, nonHispanic blacks and Hispanics showed a greater desire for information and a chance to discuss QOL information had greater trust in their children's physicians than other information after adjusting for covariates $(P<0.05)$.

Conclusions: Among children with life-limiting conditions, QOL is the most frequently desired information that parents would like to receive from physicians as part of shared decisionmaking. Parents' desire for QOL information is associated with greater trust in their children's physicians.

Keywords: children, information, life-limiting condition, quality of life, shared decisionmaking

\section{Introduction}

In the US, about 50,000 infants, children, and adolescents die from various conditions every year, ${ }^{1}$ and an estimated 500,000 children are coping with life-limiting conditions (LLCs). ${ }^{2}$ For children with LLCs, shared decision-making among physicians, parents, and affected children is critical in the course of their care. Parents of children with LLCs and the children themselves who wish to make decisions about treatment usually need information that is useful to address their concerns about health and health care.

The literature suggests that there is a great disparity in the type and amount of information that patients need versus what they actually obtain from physicians..$^{3,4}$ Physicians are generally interested in providing clinical and laboratory information,
Correspondence: I-Chan Huang PO Box 100 147, University of Florida Gainesville, FL 32610-0147, USA

Tel +I 3522657220 ext 86287

Fax + I 352265722 |

Email ichuang@ufl.edu 
whereas patients usually want to discuss patient-centered information, including quality of life (QOL) associated with treatment, spiritual beliefs, pain relief, and the meaning of life and its transitions. ${ }^{3,5}$ QOL is defined as the impact of disease and treatment on disability and daily functioning. ${ }^{6}$ Although understanding the type and preference of information exchange between patients and physicians is important, previous studies were largely based on adult rather than pediatric patient populations.

The rationale for providing information which is desired by and clear to patients is to help reduce patients' anxiety and mood disturbance, enhance sense of control, and increase satisfaction with treatment. ${ }^{7-9}$ QOL is one of the important aspects of information that patients with LLCs and caregivers frequently want to discuss because the goal of treatments, such as palliative care, is to reduce adverse symptoms and make patients' daily functioning as comfortable as possible. ${ }^{10,11}$ Additionally, clear information exchange may play a critical role in promoting patients' trust in physicians. ${ }^{12}$ Fiscella et al found that patients were likely to demonstrate greater trust in physicians if their physicians explored their patients' disease and illness experience (including symptoms, expectation of illness, and daily functioning) compared with patients whose physicians did not explore these issues. ${ }^{13}$ Hall et al concluded that trust in physicians is a driving force for discussion of sensitive issues relevant to health (eg, sexual functioning and financial concerns), promoting patient-physician communication, adherence to physicians' recommendations, and greater participation in shared decision-making. ${ }^{14}$ However, evidence of the type of information desired by parents whose children have LLCs and its association with trust in the children's physicians is limited.

It is interesting to explore the association between patient characteristics and the type of information they desire to discuss. Several factors have been identified in the literature, including patients' educational background, time since diagnosis, stage of disease, treatment regimens, and the active versus inactive role patients would like to play in decision-making. ${ }^{15-18}$ Understanding the type of information that racial/ethnic minorities want is especially important in the context of promoting clear communication. Ample evidence suggests that African-Americans and other colored people have more distrust of physicians and health care systems compared with nonHispanic whites. ${ }^{19-21}$ Less trust among these racial/ethnic minority groups provide a partial explanation for the lower rates of health care utilization and different preferences in end-of-life services compared with whites. $^{22}$
This study aimed to investigate the type of information parents of children with LLCs want to receive as part of the shared decision-making process. Specifically, we examined whether parents' sociodemographic characteristics, such as race/ethnicity, and children's health status are associated with the type of information desired by parents, and whether the desire for this information is associated with greater trust in children's physicians among racial/ethnic minority groups. We hypothesized that parents of children with LLCs will demonstrate a greater interest in discussing children's QOL than other information in the shared decision-making process, and the desire for QOL information would be associated with greater trust in children's physicians. We also hypothesized that parents of different races/ethnicities would demonstrate variation in the desired information, according to their level of trust in their children's physicians.

\section{Methods \\ Study population}

This was a cross-sectional study using data collected from parents of children who had LLCs and were enrolled in the Florida Medicaid program. We identified a sample of children aged 2-18 years with LLCs based on Florida's Medicaid guidelines for pediatric palliative care admission. We assisted the state in developing this diagnostic list using the following steps. First, using Medicaid claims and encounter data, we identified children who died between 2004 and 2006 and compiled a list of their diagnoses. ${ }^{23}$ Only the diagnoses that reflected the underlying disease (not complications associated with the disease) were retained. Second, two pediatricians at the University of Florida, who are experts in caring for children with severe/chronic disease or LLCs reviewed the list to determine if the diagnoses were potentially lifelimiting. A condition was considered as "life-limiting" if death was a possibility prior to the child's twenty-first birthday. Examples of LLCs are cancer, cystic fibrosis, and mucopolysaccharidosis. Third, based on the physicians' reviews, we revised the diagnostic list and compared our list with the diagnostic lists used in Utah, Colorado, and Kentucky to identify children with LLCs who may be eligible for palliative care programs. Diagnoses were added based on comparing the lists and with additional input from the two physician reviewers. Administrative data were queried to identify children who had LLCs.

\section{Data collection}

After the University of Florida's Institutional Review Board had approved the protocol, we sent a primer letter to a random 
sample of 936 parents whose children met our criteria for selection, followed up by telephone contact between November 2007 and April 2008. This random sample represented children with LLCs who were enrolled in the Florida Medicaid program. Among 936 parents, we were able to access 447 parents who had reliable contact information. Of the accessible group, 190 parents refused to take part in telephone interviews and 257 parents agreed to participate (response rate $57.5 \%$ ). Only one parent in the family who best knew the child's health care was interviewed. We found that social and demographic characteristics (including age, gender, race/ethnicity, and educational background) between parents who did and did not participate in this study were not statistically significant $(P>0.05)$. This response rate is similar to that of other studies conducted with families that are publically insured. ${ }^{24,25}$

\section{Measurement}

We asked parents about what information they wanted to discuss with their children's physicians for shared decisionmaking in the regular clinical visit. We used an information checklist comprised of items concerning the child's QOL or level of comfort, pain relief, spiritual beliefs, clinical diagnosis/laboratory data, change in the child's behavior due to treatment, changes in the child's appearance due to treatment, chances of recovery, advice from the physician, and advice from family/friends. A dichotomous response category (yes/no) was used for each item. This information checklist was created based on previous studies investigating the important issues that parents of children with LLCs might want to consider and discuss with their children's physicians. ${ }^{10,26}$

We used the Wake Forest Trust Scale (WFTS) to assess the parents level of trust in their children's physicians. ${ }^{14,27}$ This instrument is a 10-item unidimensional scale, capturing domains of fidelity, competence, honesty, and global trust. The psychometric properties of the WFTS are acceptable, with an alpha coefficient of 0.89 , and the measurement of trust in physicians is strongly correlated with satisfaction with care, not changing physicians, willingness to recommend the physician to friends, and not having sought second opinions. ${ }^{27}$ The measurement of scores of trust in physicians ranges from 1 to 5 , with a higher score indicating greater trust.

\section{Statistical analysis}

We used logistic regression to examine whether information parents wanted to discuss with the physician for shared decision-making is associated with parents' socioeconomic status (age, gender, educational background, and race/ethnicity), and children's health status. We measured parent proxy-report of children's health status using one item with five categories, ie, excellent, very good, good, fair, and poor. We used t-tests to examine whether the information parents wanted to discuss for shared decision-making is associated with trust in their physicians. In addition, we tested the discrepancy in the WFTS scores between parents who did versus did not want specific information based on the $P$ value (alpha level 0.05$)$ and effect size $(<0.2,0.2-0.49$, $0.5-0.79$, and $>0.8$ for a negligible, small, moderate, and large difference, respectively). ${ }^{28}$ Finally, we used linear regression to examine whether the information parents desired for shared decision-making is associated with their trust in their children's physicians, after adjusting for parents' and children's characteristics. We tested the effects of individual information and all types of information, respectively, in different regression models. We performed statistical analyses using the STATA 9.0.

\section{Results \\ Sample characteristics}

Table 1 shows the characteristics of the study subjects. Mean age of the parents was 43 years (standard deviation [SD] 11.9) and mean age of the children was 12 years (SD 5.5). The majority of parents had high school $(35 \%)$ or some college education (42\%). The racial/ethnic composition of the parents was $43 \%$ nonHispanic white, $31 \%$ nonHispanic black, and $26 \%$ Hispanic.

Table I Subject characteristics $(n=266)$

\begin{tabular}{ll}
\hline & Mean (SD) \\
\hline Parent's age (years) & 43.1 (I I.9) years \\
Child's age (years) & 11.5 (5.5) years \\
Child's gender & 55.5 \\
Male (\%) & 44.5 \\
Female (\%) & \\
Parent's race/ethnicity & 43.3 \\
NonHispanic white & 31.1 \\
NonHispanic black & 25.6 \\
Hispanic & \\
Parent's educational background & 22.8 \\
Below high school & 35.0 \\
High school & 42.1 \\
Undergraduate or above & \\
Child's general health status & \\
(self-reported by parent) & 10.4 \\
Poor & 21.5 \\
Fair & 37.5 \\
Good & 17.1 \\
Very good & 13.6 \\
Excellent & \\
\hline
\end{tabular}




\section{Type of information wanted}

Table 2 shows the distribution of information that parents wanted to discuss for shared decision-making with their children's physicians. About $95 \%$ of parents wanted to discuss QOL, followed by chances of recovery (88\%), advice from the physician $(88 \%)$, and pain relief (84\%). Seventy-eight percent of parents wanted information on clinical diagnosis/ laboratory data. In contrast, fewer parents wanted information on changes in the child's behavior due to treatment (59\%), spiritual beliefs $(51 \%)$, changes in the child's appearance due to treatment (49\%), and advice from family members/ friends (49\%).

\section{Parental characteristics and information wanted}

Table 3 shows the relationships between information that parents wanted to discuss and their sociodemographic characteristics and children's health status. Information that parents wanted varied according to their racial/ethnic and educational background and their children's health status. Compared with nonHispanic white parents, nonHispanic black and Hispanic parents had a greater preference for discussing information related to chances of recovery (odds ratios [OR] 3.7 and 5.8, respectively), spiritual beliefs (OR 3.0 and 3.6, respectively), and changes in the child's appearance due to treatment (OR 5.9 and 3.0, respectively, all $P<0.05$ ). Compared with nonHispanic white parents, Hispanic and nonHispanic black parents also desired information on clinical diagnosis/ laboratory data and on changes in the child's behavior due to treatment. However, the associations were only significant among Hispanic parents $(P<0.05)$.

Compared with parents with a college degree or higher, those with less than a high school education demonstrated greater preference for almost all information, especially pain relief (OR 7.6), spiritual beliefs (OR 2.3), and changes in the child's appearance due to treatment (OR 2.1, all

Table 2 Information desired by parents for shared decisionmaking

\begin{tabular}{ll}
\hline Type of information & $\%$ \\
\hline Quality of life & 94.5 \\
Chances of recovery & 87.8 \\
Advice from the physicians & 87.8 \\
Pain relief & 83.9 \\
Clinical diagnosis/laboratory data & 78.0 \\
Changes in the child's behavior due to treatment & 58.7 \\
Spiritual belief & 51.2 \\
Changes in the child's appearance due to treatment & 49.2 \\
Advice from family/friends & 48.8 \\
\hline
\end{tabular}

$P<0.05)$. Similarly, parents of children with worse health status showed a greater preference for almost all information, especially pain relief(OR 3.5), spiritual beliefs (OR 2.3), and changes in the child's behavior due to treatment (OR 2.2), compared with parents of children with better health status (all $P<0.05$ ).

\section{Information wanted and trust in children's physicians}

Table 4 shows the relationship between information parents wanted to discuss and their trust in children's physicians based on bivariate analyses. Parents who wanted to discuss QOL information had greater trust in their children's physicians compared with parents who did not want to discuss QOL $(P<0.05$ and effect size 1.1). Likewise, parents who wanted advice from the physician on pain relief and clinical diagnosis/laboratory data had greater trust in their children's physicians compared with those who did not (all $P<0.05$ ). However, the magnitude in discrepancies on the WPTS scores was small (all with effect size approximately 0.4).

Table 5 shows the association between parents' sociodemographic characteristics and their trust in children's physicians conditioning on the type of information that was significantly associated with trust in physicians (see Table 4). Model 1 is a null model explaining the association between parents' and children's characteristics and trust in physicians. Models 2-6 added further information on QOL, advice from the physician, pain relief, and clinical diagnosis/laboratory data, respectively, as well as the four types of information, along with the variables contained in Model 1.

Model 1 shows that parents of older children with LLCs and nonHispanic black parents (versus nonHispanic white) had significantly less trust in physicians, respectively (both $P<0.05)$. Although Hispanic parents reported greater trust in physicians compared with nonHispanic white parents, the association was not statistically significant $(P>0.05)$.

Adding preference of QOL information was associated with an increasing level of trust in physicians by nonHispanic black and Hispanic parents compared with nonHispanic white parents (Model 2). However, the racial disparities for trust in physicians still exist; for example, nonHispanic black parents showed less trust in physicians (Model 2). Similarly, adding preference for receiving advice from the physician alone (Model 3) and all information types (including QOL, advice from the physician, pain relief, and clinical diagnosis/ laboratory data, Model 6) reduced the disparity in trust of physicians between nonHispanic black and nonHispanic white parents. 


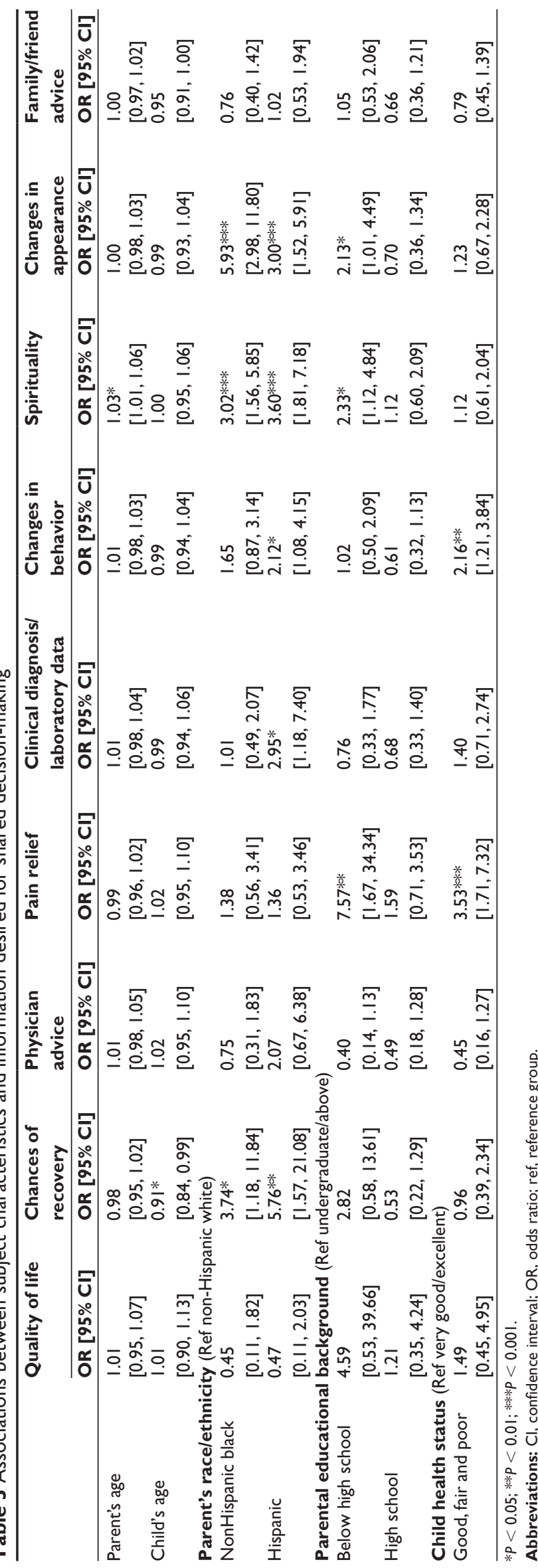

Table 5 also shows that preference for discussing QOL (Model 2), pain relief (Model 4), clinical diagnosis/laboratory data by parents (Model 5), but not advice from the physician (Model 3), were associated with greater trust in physicians $(P<0.05)$. However, when adding all information into the model (Model 6), only the desire for QOL information was associated with greater trust in physicians $(P<0.05)$.

\section{Discussion}

This study is among one of very few to investigate the type of information that parents of children with LLCs want to discuss for shared decision-making, while also exploring its association with parents' trust in their children's physicians. Our findings expand the knowledge in the pediatric literature in the following ways. First, children's QOL was the most frequently desired information that parents wanted to know and incorporate into the shared decision-making process. Second, nonHispanic black and Hispanic parents show a greater preference for information on chances of recovery, spiritual beliefs, and changes in the child's appearance due to treatment compared with non-Hispanic whites. All races/ ethnicities desired and wanted to discuss QOL information to an equal extent. Third, compared with nonHispanic white parents, nonHispanic blacks demonstrated less trust in their children's physicians. Parents who wanted QOL information had greater trust in their children's physicians than those who wanted other information.

Our study is in line with another pediatric study reporting that parents wanted QOL information more than any other type of information when making decisions for children who require intensive health care. ${ }^{10}$ This finding is not surprising because empiric studies have indicated that QOL is always the ultimate concern with LLCs, ${ }^{11}$ and assessing and discussing QOL can help physicians identify patients' unexpected health problems (especially psychosocial functioning), leading to improved parent-doctor communication, trust in the physician, and satisfaction with decision-making. ${ }^{5}$ Fiscella et al reported that trust in the physician is significantly related to the physician's verbal behavior. ${ }^{13}$ Specifically, they found that if physicians ask questions and respond to patients' concerns about symptoms and daily functioning, patients tend to report greater trust in those physicians than in physicians who explore other issues, such as family, social network, and work issues. ${ }^{13}$

Unfortunately, in routine clinical practice, physicians are interested in discussing biomedical/technical issues (eg, results of blood tests and doses of chemotherapy) with patients and, to a lesser degree, issues related to QOL. 5 
Table 4 Associations between information desired for shared decision-making and trust in physician

\begin{tabular}{|c|c|c|c|}
\hline Type of information & Yes & No & $\begin{array}{l}\text { Difference } \\
\text { (effect size }^{\dagger} \text { ) }\end{array}$ \\
\hline Quality of life & 43.27 & 37.15 & $6.12 * * *(1.06)$ \\
\hline Chances of recovery & 43.00 & 42.63 & $0.33(0.06)$ \\
\hline Advice from physicians & 43.19 & 41.05 & $2.13^{*}(0.37)$ \\
\hline Pain relief & 43.28 & 41.05 & $2.23 *(0.39)$ \\
\hline Clinical diagnosis/laboratory data & 43.37 & 41.33 & $2.05 *(0.36)$ \\
\hline $\begin{array}{l}\text { Changes in the child's behavior } \\
\text { due to treatment }\end{array}$ & 43.00 & 42.81 & $0.20(0.03)$ \\
\hline Spiritual beliefs & 42.37 & 43.51 & $-0.14(-0.19)$ \\
\hline $\begin{array}{l}\text { Changes in the child's appearance } \\
\text { due to treatment }\end{array}$ & 42.41 & 43.43 & $-1.02(-0.18)$ \\
\hline Advice from family/friends & 42.87 & 42.90 & $-0.11(-0.02)$ \\
\hline
\end{tabular}

Physicians also frequently use terminology that patients may not understand..$^{29,30}$ This implies physicians vary in their capability to elicit relevant information from patients, especially on psychosocial and QOL issues. ${ }^{31,32}$ We suggest that identification of QOL issues as the most frequently preferred information is just the first step. The next step would be to make physicians aware of the strong desire by parents to discuss QOL issues, and help physicians develop appropriate ways of presenting the complex management options and benefits/risks associated with QOL to their patients.

We found that different racial/ethnic groups emphasized the significance of information variably during the patientphysician encounter. Cultural values may serve as filters to weigh information and choose treatments. For example, nonHispanic black patients are more likely than nonHispanic whites to request life-sustaining therapy, intensive care unit admission, artificial ventilation, and tube feeding, and are less likely to sign advance directives or do-not-resuscitate orders. ${ }^{33-36}$ Our research, along with another recent study, ${ }^{37}$ found that nonHispanic whites wanted more information on medical options and prognosis, whereas nonHispanic blacks requested more spiritually focused information and overwhelmingly endorsed physician-initiated discussions about the role of spirituality in the decision-making process.

Reducing the disparity between trust in physicians and health outcomes between nonHispanic whites and minority

Table 5 Associations between subject characteristics and information desired by parents for shared decision-making and trust in physicians

\begin{tabular}{|c|c|c|c|c|c|c|}
\hline & $\begin{array}{l}\text { Model I } \\
\text { Null }\end{array}$ & $\begin{array}{l}\text { Model } 2 \\
\text { Quality of life }{ }^{\dagger}\end{array}$ & $\begin{array}{l}\text { Model } 3 \\
\text { Physician advice }^{\dagger}\end{array}$ & $\begin{array}{l}\text { Model } 4 \\
\text { Pain relief }\end{array}$ & $\begin{array}{l}\text { Model } 5 \\
\text { Clinical diagnosis/ } \\
\text { laboratory data }^{\dagger}\end{array}$ & $\begin{array}{l}\text { Model } 6 \\
\text { All information } \\
\text { combined }^{\dagger}\end{array}$ \\
\hline & $\mathrm{RC}[95 \% \mathrm{Cl}]$ & $\mathrm{RC}[95 \% \mathrm{Cl}]$ & $\mathbf{R C}[95 \% \mathrm{Cl}]$ & $\mathbf{R C}[95 \% \mathrm{Cl}]$ & $\mathrm{RC}[95 \% \mathrm{Cl}]$ & $\mathrm{RC}[95 \% \mathrm{Cl}]$ \\
\hline Quality of life & & $\begin{array}{l}6.07 * * * \\
{[2.97,9.17]}\end{array}$ & & & & $\begin{array}{l}4.73 * * \\
{[1.46,8.00]}\end{array}$ \\
\hline Physician advice & & & $\begin{array}{l}1.91 \\
{[-0.26,4.09]}\end{array}$ & & & $\begin{array}{l}0.44 \\
{[-1.85,2.74]}\end{array}$ \\
\hline Pain relief & & & & $\begin{array}{l}3.08 * * \\
{[1.08,5.08]}\end{array}$ & & $\begin{array}{l}1.80 \\
{[-0.31,3.91]}\end{array}$ \\
\hline $\begin{array}{l}\text { Clinical diagnosis/ } \\
\text { laboratory data }\end{array}$ & & & & & $\begin{array}{l}2.18 * \\
{[0.43,3.92]}\end{array}$ & $\begin{array}{l}\text { I.II } \\
{[-0.77,3.00]}\end{array}$ \\
\hline Parent's age & $\begin{array}{l}-0.04 \\
{[-0.11,0.02]}\end{array}$ & $\begin{array}{l}-0.04 \\
{[-0.11,0.02]}\end{array}$ & $\begin{array}{l}-0.04 \\
{[-0.11,0.02]}\end{array}$ & $\begin{array}{l}-0.04 \\
{[-0.10,0.03]}\end{array}$ & $\begin{array}{l}-0.05 \\
{[-0.11,0.02]}\end{array}$ & $\begin{array}{l}-0.04 \\
{[-0.11,0.02]}\end{array}$ \\
\hline Child's age & $\begin{array}{l}-0.15^{*} \\
{[-0.29,-0.01]}\end{array}$ & $\begin{array}{l}-0.15^{*} \\
{[-0.29,-0.01]}\end{array}$ & $\begin{array}{l}-0.15^{*} \\
{[-0.29,-0.01]}\end{array}$ & $\begin{array}{l}-0.16^{*} \\
{[-0.29,-0.02]}\end{array}$ & $\begin{array}{l}-0.14 * \\
{[-0.28,-0.01]}\end{array}$ & $\begin{array}{l}-0.15^{*} \\
{[-0.29,-0.02]}\end{array}$ \\
\hline \multicolumn{7}{|c|}{ Parent's race/ethnicity (Ref nonHispanic white) } \\
\hline NonHispanic Black & $\begin{array}{l}-2.03^{*} \\
{[-3.78,-0.28]}\end{array}$ & $\begin{array}{l}-1.79 * \\
{[-3.49,-0.08]}\end{array}$ & $\begin{array}{l}-1.95^{*} \\
{[-3.70,-0.21]}\end{array}$ & $\begin{array}{l}-2.15^{*} \\
{[-3.87,-0.43]}\end{array}$ & $\begin{array}{l}-2.03 * \\
{[-3.76,-0.30]}\end{array}$ & $\begin{array}{l}-1.90 * \\
{[-3.60,-0.20]}\end{array}$ \\
\hline Hispanic & $\begin{array}{l}0.06 \\
{[-1.74,1.86]}\end{array}$ & $\begin{array}{l}0.28 \\
{[-1.47,2.04]}\end{array}$ & $\begin{array}{l}-0.07 \\
{[-1.87,1.73]}\end{array}$ & $\begin{array}{l}-0.04 \\
{[-1.81,1.73]}\end{array}$ & $\begin{array}{l}-0.25 \\
{[-2.05,1.55]}\end{array}$ & $\begin{array}{l}-0.02 \\
{[-1.79,1.75]}\end{array}$ \\
\hline \multicolumn{7}{|c|}{ Parent's education background (Ref undergraduate/above) } \\
\hline Below high school & $\begin{array}{l}-1.56 \\
{[-3.46,0.34]}\end{array}$ & $\begin{array}{l}-1.90 * \\
{[-3.76,-0.05]}\end{array}$ & $\begin{array}{l}-1.38 \\
{[-3.28,0.52]}\end{array}$ & $\begin{array}{l}-2.12^{*} \\
{[-4.02,-0.22]}\end{array}$ & $\begin{array}{l}-1.47 \\
{[-3.35,0.41]}\end{array}$ & $\begin{array}{l}-2.06 * \\
{[-3.95,-0.17]}\end{array}$ \\
\hline High school & $\begin{array}{l}-1.12 \\
{[-2.81,0.58]}\end{array}$ & $\begin{array}{l}-1.18 \\
{[-2.83,0.47]}\end{array}$ & $\begin{array}{l}-0.98 \\
{[-2.68,0.7 I]}\end{array}$ & $\begin{array}{l}-1.38 \\
{[-3.05,0.30]}\end{array}$ & $\begin{array}{l}-1.01 \\
{[-2.69,0.67]}\end{array}$ & $\begin{array}{l}-1.23 \\
{[-2.89,0.43]}\end{array}$ \\
\hline \multicolumn{7}{|c|}{ Child health status (Ref very good/excellent) } \\
\hline Good, fair and poor & $\begin{array}{l}0.32 \\
{[-1.26,1.91]}\end{array}$ & $\begin{array}{l}0.20 \\
{[-1.34,1.74]}\end{array}$ & $\begin{array}{l}0.45 \\
{[-1.13,2.03]}\end{array}$ & $\begin{array}{l}-0.21 \\
{[-1.81,1.38]}\end{array}$ & $\begin{array}{l}0.22 \\
{[-1.35,1.79]}\end{array}$ & $\begin{array}{l}-0.11 \\
{[-1.69,1.47]}\end{array}$ \\
\hline
\end{tabular}

†Only including those with information $P<0.05$ and effect size $>0.2$ in bivariate analysis (see Table 4); $* P<0.05 ; * * P<0.0$ I; $* * * P<0.00$ I.

Abbreviation: RC, regression coefficient; ref, reference group. 
groups is the top priority of our health care policy. ${ }^{38}$ Compared with nonHispanic white patients, physicians engaged in 33\% less patient-centered communication with nonHispanic black patients. ${ }^{39}$ Additionally, compared with nonHispanic whites, physicians provided less information to racial/ethnic minorities and less frequently solicited their involvement in decision-making. ${ }^{40,41}$ We would suggest that if physicians can explore, customize, and provide patientcentered information (on issues such as QOL and spiritual beliefs) to racial/ethnic minorities, this may increase parents' trust in physicians. The provision of health information should take into account cultural literacy which allows minority groups to recognize, understand, and act on culturally sensitive health information in a better way. ${ }^{42}$

Although our finding makes intuitive sense that exchanging patient-centered information (eg, QOL) is related to greater trust in physicians, we advise caution in interpreting this finding. We cannot claim conclusively that discussion of QOL information improves trust in physicians because the present study (like many other studies of this sort) ${ }^{43-45}$ is based on a cross-sectional design. It is possible that parents who desired QOL information for shared decision-making are those who already trust their physicians more than those who do not want this information. Further longitudinal studies are needed to investigate the causal pathway between desire for and use of QOL information. as well as trust in physicians among parents whose children have LLCs.

Some potential limitations of our study merit attention. First, this study was restricted to children who were enrolled in Florida's Medicaid program. Our population was at or below $100 \%$ of the federal poverty level. Although the generalizability of our findings may be limited, this population is important to assess because of their greater risk of impaired health status due to poor socioeconomic circumstances. Second, this study only examined the association between information wanted by parents and their trust in physicians by accounting for parents' sociodemographic characteristics and children's self-reported health status. The observed association may be confounded by unmeasured underlying characteristics, such as parents' knowledge about end-of-life care, parents' mental health status, the role that parents took in the decision-making process, and the severity and duration of the child's illness. ${ }^{16,18,46}$ These characteristics may influence parents to seek out specific information, such as QOL, that may affect their level of trust in physicians. Finally, we investigated information that parents want without rigorously exploring its relative importance. Understanding the relative importance of topics related to shared decision-making and their impact on physician trust would be useful for designing interventions. Advanced methodology, such as conjoint analysis, can be used to explore this issue. ${ }^{47}$

In conclusion, parents wanting to discuss QOL information as part of shared decision-making for their children's LLCs had greater trust in their children's physicians than those who deemed other areas of higher importance. This was especially evident in the racial/ethnic minority groups. Further research is encouraged to determine whether interventions designed to enhance patients' knowledge, understanding, and management of QOL information for treatment of illness can improve trust in physicians.

\section{Acknowledgment}

This study is supported in part by the grant of K23 HD057146 from the National Institutes of Health/National Institute of Child Health and Human Development.

\section{Disclosure}

The authors declare that they have no conflicts of interest in this work.

\section{References}

1. Hamilton BE, Minino AM, Martin JA, Kochanek KD, Strobino DM, Guyer B. Annual summary of vital statistics: 2005. Pediatrics. 2007; 119(2):345-360.

2. Himelstein BP, Hilden JM, Boldt AM, Weissman D. Pediatric palliative care. N Engl J Med. 2004;350(17):1752-1762.

3. Degner LF, Davison BJ, Sloan JA, Mueller B. Development of a scale to measure information needs in cancer care. J Nurs Meas. 1998;6(2): $137-153$.

4. Vogel BA, Helmes AW, Hasenburg A. Concordance between patients' desired and actual decision-making roles in breast cancer care. Psychooncology. 2008;17(2):182-189.

5. Detmar SB, Muller MJ, Wever LD, Schornagel JH, Aaronson NK. The patient-physician relationship. Patient-physician communication during outpatient palliative treatment visits: An observational study. JAMA. 2001;285(10):1351-1357

6. Kaplan RM. Quality of life measurement. In: Karoly P, editor. Measurement Strategies in Health Psychology. New York, NY: John Wiley; 1985.

7. Mallinger JB, Griggs JJ, Shields CG. Patient-centered care and breast cancer survivors' satisfaction with information. Patient Educ Couns. 2005;57(3):342-349.

8. van der Molen B. Relating information needs to the cancer experience: 1. Information as a key coping strategy. Eur J Cancer Care. 1999;8(4): 238-244.

9. McCaughan E, McKenna H. Never-ending making sense: Towards a substantive theory of the information-seeking behaviour of newly diagnosed cancer patients. J Clin Nurs. 2007;16(11):2096-104.

10. Meyer EC, Burns JP, Griffith JL, Truog RD. Parental perspectives on end-of-life care in the pediatric intensive care unit. Crit Care Med. 2002;30(1):226-231.

11. Kaasa S, Loge JH. Quality-of-life assessment in palliative care. Lancet Oncol. 2002;3(3):175-182.

12. Hinds PS, Oakes L, Quargnenti A, et al. An international feasibility study of parental decision making in pediatric oncology. Oncol Nurs Forum. 2000;27(8):1233-1243. 
13. Fiscella K, Meldrum S, Franks P, et al. Patient trust: Is it related to patient-centered behavior of primary care physicians? Med Care. 2004; 42(11):1049-1055.

14. Hall MA, Dugan E, Zheng B, Mishra AK. Trust in physicians and medical institutions: What is it, can it be measured, and does it matter? Milbank Q. 2001;79(4):613-639.

15. Blanchard CG, Labrecque MS, Ruckdeschel JC, Blanchard EB. Information and decision-making preferences of hospitalized adult cancer patients. Soc Sci Med. 1988;27(11):1139-1145.

16. Cassileth BR, Zupkis RV, Sutton-Smith K, March V. Information and participation preferences among cancer patients. Ann Intern Med. 1980;92(6):832-836.

17. Degner LF, Sloan JA. Decision making during serious illness: What role do patients really want to play? J Clin Epidemiol. 1992;45(9): 941-950.

18. Hack TF, Degner LF, Dyck DG. Relationship between preferences for decisional control and illness information among women with breast cancer: A quantitative and qualitative analysis. Soc Sci Med. 1994; 39(2):279-289.

19. Halbert CH, Armstrong K, Gandy OH Jr, Shaker L. Racial differences in trust in health care providers. Arch Intern Med. 2006;166(8):896-901.

20. Saha S, Freeman M, Toure J, Tippens KM, Weeks C, Ibrahim S. Racial and ethnic disparities in the VA health care system: A systematic review. J Gen Intern Med. 2008;23(5):654-671.

21. Rajakumar K, Thomas SB, Musa D, Almario D, Garza MA. Racial differences in parents' distrust of medicine and research. Arch Pediatr Adolesc Med. 2009;163(2):108-114.

22. LaVeist TA, Nickerson KJ, Bowie JV. Attitudes about racism, medical mistrust, and satisfaction with care among African American and white cardiac patients. Med Care Res Rev. 2000;57 Suppl 1:146-161.

23. Knapp CA, Madden VL, Curtis CM, et al. Partners in care: Together for kids: Florida's model of pediatric palliative care. J Palliat Med. 2008;11(9):1212-1220.

24. Anarella J, Roohan P, Balistreri E, Gesten F. A survey of Medicaid recipients with asthma: Perceptions of self-management, access and care. Chest. 2004;125(4):1359-1367.

25. Dick AW, Brach C, Allison RA, et al. SCHIP's impact in three states: How do the most vulnerable children fare? Health Aff (Millwood). 2004;23(5):63-75.

26. Pyke-Grimm KA, Degner L, Small A, Mueller B. Preferences for participation in treatment decision making and information needs of parents of children with cancer: A pilot study. J Pediatr Oncol Nurs. 1999;16(1):13-24.

27. Hall MA, Camacho F, Dugan E, Balkrishnan R. Trust in the medical profession: Conceptual and measurement issues. Health Serv Res. 2002;37(5):1419-1439

28. Cohen J. Statistical Power Analysis for the Behavioral Sciences. 2nd ed. Hillsdale, NJ: Lawrence Erlbaum Associates; 1988.

29. Chaitchik S, Kreitler S, Shaked S, Schwartz I, Rosin R. Doctor-patient communication in a cancer ward. J Cancer Educ. 1992;7(1):41-54.

30. Gattellari M, Butow PN, Tattersall MH, Dunn SM, MacLeod CA. Misunderstanding in cancer patients: Why shoot the messenger? Ann Oncol. 1999;10(1):39-46.

31. Passik SD, Dugan W, McDonald MV, Rosenfeld B, Theobald DE, Edgerton S. Oncologists' recognition of depression in their patients with cancer. J Clin Oncol. 1998;16(4):1594-1600.

Patient Related Outcome Measures

\section{Publish your work in this journal}

Patient Related Outcome Measures is an international, peer-reviewed, open access journal focusing on treatment outcomes specifically relevant to patients. All aspects of patient care are addressed within the journal and practitioners from all disciplines are invited to submit their work as well as healthcare researchers and patient support groups. Areas covered will Submit your manuscript here: http://www.dovepress.com/patient-related-outcome-measures-journal
32. Fallowfield L, Ratcliffe D, Jenkins V, Saul J. Psychiatric morbidity and its recognition by doctors in patients with cancer. Br J Cancer. 2001; 84(8):1011-1015.

33. Garrett JM, Harris RP, Norburn JK, Patrick DL, Danis M. Lifesustaining treatments during terminal illness: Who wants what? J Gen Intern Med. 1993;8(7):361-368.

34. McKinley ED, Garrett JM, Evans AT, Danis M. Differences in end-oflife decision making among black and white ambulatory cancer patients. J Gen Intern Med. 1996;11(11):651-656.

35. Goodlin SJ, Zhong Z, Lynn J, et al. Factors associated with use of cardiopulmonary resuscitation in seriously ill hospitalized adults. JAMA. 1999;282(24):2333-2339.

36. True G, Phipps EJ, Braitman LE, Harralson T, Harris D, Tester W. Treatment preferences and advance care planning at end of life: The role of ethnicity and spiritual coping in cancer patients. Ann Behav Med. 2005;30(2):174-179.

37. Shrank WH, Kutner JS, Richardson T, Mularski RA, Fischer S, Kagawa-Singer M. Focus group findings about the influence of culture on communication preferences in end-of-life care. J Gen Intern Med. 2005;20(8):703-709.

38. United States Department of Health and Human Services. Healthy People 2010. Washington, DC: US Dept. of Health and Human Services; 2000. Available at: http://www.healthypeople.gov/. Accessed on Jul 10, 2010

39. Johnson RL, Roter D, Powe NR, Cooper LA. Patient race/ethnicity and quality of patient-physician communication during medical visits. $\mathrm{Am}$ J Public Health. 2004;94(12):2084-2090.

40. Kaplan SH, Gandek B, Greenfield S, Rogers W, Ware JE. Patient and visit characteristics related to physicians' participatory decisionmaking style. Results from the Medical Outcomes Study. Med Care. 1995;33(12):1176-1187.

41. Cooper-Patrick L, Gallo JJ, Gonzales JJ, et al. Race, gender, and partnership in the patient-physician relationship. JAMA. 1999;282(6): 583-589.

42. Institute of Medicine Committee on Health Literacy. In: NielsenBohlman L, Panzer AM. Kindig DA, editors. Health Literacy: A Prescription to End Confusion. Washington, DC: National Academies Press; 2004

43. Thom DH, Kravitz RL, Bell RA, Krupat E, Azari R. Patient trust in the physician: Relationship to patient requests. Fam Pract. 2002; 19(5):476-483.

44. Ireson CL, Slavova S, Steltenkamp CL, Scutchfield FD. Bridging the care continuum: Patient information needs for specialist referrals. $B M C$ Health Serv Res. 2009;9:163.

45. Tremolada M, Bonichini S, Altoe G, Pillon M, Carli M, Weisner TS. Parental perceptions of health-related quality of life in children with leukemia in the second week after the diagnosis: A quantitative model. Support Care Cancer. 2010 Mar 13. [Epub ahead of print].

46. Hummelinck A, Pollock K. Parents' information needs about the treatment of their chronically ill child: A qualitative study. Patient Educ Couns. 2006;62(2):228-234.

47. Ryan M, Farrar S. Using conjoint analysis to elicit preferences for health care. BMJ. 2000;320(7248):1530-1533.

include: Quality of life scores; Patient satisfaction audits; Treatment outcomes that focus on the patient; Research into improving patient outcomes; Hypotheses of interventions to improve outcomes; Short communications that illustrate improved outcomes; Case reports or series that show an improved patient experience; Patient journey descriptions or research. 